Imanishi-Kari's notebooks at face value. "There was no way for us to tell if the data were real - we couldn't analyse the counter tapes like the Secret Service," she says.

"Everything has changed so much in the last three years since the Tufts probe," Huber says. "Everybody is so much more sensitized. When these things come up now they're taken much more seriously." She points out that the committee on which she served was created informally in less than a week to examine O'Toole's accusations. NIH has since issued guidelines for the creation of formal university panels to investigate such cases of alleged scientific misconduct.

As evidence of misconduct emerged, Baltimore came under increasing fire for his steadfast refusal to accept the possibility that Imanishi-Kari had fabricated critical data in the Cell paper. Former NIH director James Wyngaarden admonished Baltimore and his co-authors in a 1989 letter: "[You] never met to consider seriously the allegations or to reexamine the data.... Such an analysis... may well have made a full examination unnecessary." But Baltimore says that confusion in Imanishi-Kari's records was partly to blame. "The whole investigation has been very difficult because of the sloppy methods used," he says. "The evidence mounted, but I did not find it convincing. Until I was sure, I was not going to accuse her of something improper."

"Clearly the NIH has done a remarkable job" with the draft report, he says. "I find it much more convincing than anything previously said. The evidence that the gammacounter tapes were produced before the mice were born is very disturbing."

OSI took a less charitable view of Baltimore. The draft report quotes him as accusing OSI of forcing Imanishi-Kari into misconduct by requiring that she publish additional data in the form of a correction to support the claims of the Cell paper. OSI has since concluded that the data in that correction were fabricated.

“... [I]n my mind you can make up anything that you want in your notebooks, but you can't call it fraud if it wasn't published", Baltimore told the OSI team of investigators. "Now, you managed to trick us into publishing - sort of tricked Thereza - into publishing a few numbers and now you're going to go back and see if you can produce those as fraud. But I think you should see that was a forced situation ...." The draft OSI report describes that statement as "extraordinary".

Baltimore says that when he told the OSI team of investigators that researchers could ethically "tnake up anything" in their notebooks, he was not referring to data. He also distances himself from the rest of the statement. "It was clearly misconduct to discuss data that didn't exist", he explains. "It's not any less or more wrong because Thereza was forced to publish it."

Christopher Anderson

\title{
AIDS trials questioned
}

\section{Washington}

REPORTS that past US collaboration with French AIDS researcher Daniel Zagury (see Nature 350, 179; 21 March 1991) may not have complied with the requirements of US law on research with human subjects has led the US National Institutes of Health (NIH) to the unusual step of suspending all collaboration with Zagury and the institutions with which he is affiliated.

The allegations against Zagury have been made by journalist John Crewdson of the Chicago Tribune, and amount to the assertion that volunteers in work with putative AIDS vaccines had not been subjected to the full requirements of ethics committee review specified by US law. As long ago as 1987, Zagury reported the injection of a putative vaccine into himself.

US policy requires layers of approval for all collaborative research, whether it involves direct work with patients, the sharing of research materials or even testing of blood. NIH are in the midst of a broad examination of their policy on the ethical requirements of international research collaborations with human subjects.

A report on overall policy requirements, and a decision in the Zagury case, are expected soon. Meanwhile, NIH officials have banned all NIH scientists from collaboration with Zagury and with the institutions at which he is working on an AIDS vaccine. These include the Université Pierre et Marie Curie and its affiliated hospitals in Paris, the Cliniques Universitaires de Kinshasa in Zaire and the Institut National de Recherches Biomedicales in Zaire.

During the past several years, Zagury's collaborators in the United States have included Robert C. Gallo of the National Cancer Institute, other NCI researchers, Takas Papas, an NCI contractor, and Bernard Moss of the National Institute of Allergy and Infectious Diseases.

A preliminary NIH inquiry indicates, for instance, that before Moss sent Zagury recombinant vaccinia incorporating the env gene from Gallo's widely distributed IIIB strain of AIDS virus, appropriate ethical approvals were in hand from the allergy institute's committee, the French ethical committee and the US Food and Drug Administration, which authorized shipment of vaccinia in response to a request from the French National Health Laboratory.

However, informed consent documents may not have been approved by all the committees specified in the law.

Another allegation is that Gallo tested blood samples that Zagury drew from military personnel in Zaire without asking for the approval of the ethical committee at NIH. Gallo says, "This is true. I didn't know you had to have approval to study blood samples even if you were not involved in the clinical research." Zagury did have approval from officials in Zaire. NIH ethics officials say they now realize that there are very few NIH researchers who know that, particularly those whose research does not bring them into contact with patients.

It is also alleged that NIH are in violation of their own rules because their researchers sent Zagury materials intended for animal and laboratory studies that were actually used in human vaccine trials. This Zagury vigorously denies. In a 6 March 'certificate' to the NIH, he wrote "I never administered to human individuals during clinical trials performed in Zaire or in France any reagents provided by the NCI".

Crewdson's evidence to the contrary appears in a Chicago Tribune article that, referring to Zagury's most recent study, quotes one participant as saying that the husband of Zagury's principal collaborator had said, "the stuff we were being injected with was from Gallo's laboratory".

Perhaps the most serious ethical question goes back to Zagury's experiments in 1986 and 1987 with an early AIDS vaccine preparation that he tried out on himself and on what he described (in Nature) as "a small group of Zairians, all of whom were HIV-seronegative volunteers and immunologically normal . .." (Nature 326, 249; 1987).

What the paper fails to mention, it now emerges, is that the Zairian volunteers were all young children whose fathers had died of AIDS and whose mothers were infected. Zagury says he obtained informed consent from the mothers, who "begged" him to protect their children. NIH officials say it is doubtful the experiment would have won ethical approval, based on what they know now.

NIH's own report says that, in 1986, Moss sent Zagury "a large quantity" of recombinant vaccinia virus (V25) for use in animals. It is now reported that Zagury used this recombinant vaccinia virus to make his first human AIDS vaccine, a fact that Moss reported to the NIH's OPRR. The NIH preliminary report says only that "OPRR is aware of Dr Zagury's unauthorized use of the vaccinia virus in humans. Therefore, we will not discuss it further." OPRR officials decline to comment on their own behaviour.

But they have appointed a committee to look into the current case, naming Seymour Klebanoff of the University of Washington in Seattle as its chairman. Members of that committee are reported already to have submitted their report to OPRR. One of them noted privately that the real challenge is sorting out procedures in which no ethical standards were violated, even though appropriate committee review was not secured, from those in which the requirements were effectively ignored. Nevertheless, in the final analysis, NIH are going to have to put their house in order and make their rules unambiguously clear.

Barbara J. Culliton 